\title{
Effects of Film Variety on the Amounts of Carboxylic Acids from Electron Beam Irradiated Polyethylene Film
}

\author{
Keiko Azuma, Yoshikazu TanaKa, Hirotaka Tsunoda,* \\ Takashi Hirata and Takasuke IsHITANI \\ National Food Research Institute, \\ P.O. Box 11, Yatabe, Tsukuba, Ibaraki 305, Japan \\ * Dai Nippon Printing Co., Ltd., \\ 591-10, Kamihirose, Sayama, Saitama 350-13, Japan
}

Received December 27, 1983

\begin{abstract}
The amounts of carboxylic acids released from electron beam irradiated polyethylene film, which can be indicators of the intensity of off-odor, were examined. The conditions for trapping acetic acid, propionic acid, $n$-butyric acid, and $n$-valeric acid from two grams of film irradiated with a dose of $20 \mathrm{kGy}$ in air were established as follows; carboxylic acids volatilized at $80^{\circ} \mathrm{C}$ from irradiated film were concentrated on Tenax GC by passing nitrogen gas at a flow rate of $20 \mathrm{ml} / \mathrm{min}$ for 30 minutes. The amounts of carboxylic acids varied considerably depending upon the properties of the resin, the presence of additives, etc. Without additives, the total amounts of the acids from the film which gave the strongest off-odor was three times the total amounts of the acids from the film which gave the weakest off-odor. The addition of butylated hydroxytoluene to film reduced remarkably the formation of carboxylic acids.
\end{abstract}

Sterilization of many heat-sensitive medical products by radiation, usually $\gamma$-rays from cobalt 60 , is now widely employed as an alternative to gaseous ethylene oxide sterilization. This is because ethylene oxide sterilization may leave undesirable residues in the products. Although many polymers show various degrees of degradation after irradiation, most polymers have been reported to be stable for the generally accepted sterilizing dose $(25 \mathrm{kGy}) .^{1 \sim 3)}$

Accelerated electron beam irradiation is one of the promising techniques for the sterilization of packaging materials in the aseptic packaging system. ${ }^{4)}$ However, there is the problem that volatiles responsible for an offodor are produced. It has been reported earlier that aliphatic hydrocarbons $\left(\mathrm{C}_{3}\right.$ to $\left.\mathrm{C}_{13}\right)$, aldehydes $\left(\mathrm{C}_{2}\right.$ to $\left.\mathrm{C}_{5}\right)$, ketones $\left(\mathrm{C}_{4}\right.$ to $\left.\mathrm{C}_{8}\right)$, and carboxylic acids $\left(\mathrm{C}_{2}\right.$ to $\left.\mathrm{C}_{5}\right)$ were the main volatiles in low density polyethylene irradiated with electron beams, ${ }^{5)}$ and that carboxylic acids, such as acetic acid, propionic acid, $n$ butyric acid, and $n$-valeric acid, were mainly responsible for the off-odor. Thus, the inten- sity of off-odor from irradiated polyethylene could be estimated by the amounts of these four carboxylic acids.

Low density polyethylene varies in density, melt index, molecular weight distribution, etc. depending upon the method for polymerization of ethylene. ${ }^{6)}$ Most low density film resins also contain functional additives such as slip, antiblock, antioxidant and ultraviolet inhibitors. The nature and extent of chemical and physical changes in plastics are considered to be affected by the presence of antioxidants and other additives. ${ }^{1)}$ In this paper, the conditions for quantitatively trapping and concentrating the volatile acids released from irradiated film were investigated and the effects of the properties of the resin, the conditions for film-formation, and the presence of additives in film on the amounts of carboxylic acids were studied.

\section{EXPERIMENTAL}

1. Materials: Nine varieties of low density polyethylene film of $c a .40 \mu \mathrm{m}$ thickness were used. Table I 
Table I. Preparation of Low Density Polyethylene Film

\begin{tabular}{|c|c|c|c|c|c|c|}
\hline \multirow[b]{2}{*}{ Film } & \multicolumn{3}{|c|}{ Resin } & \multicolumn{2}{|c|}{ Film-formation } & \multirow[b]{2}{*}{ Additive } \\
\hline & $\begin{array}{c}\text { Method for } \\
\text { polymerization }\end{array}$ & Density & Melt index ${ }^{a}$ & Process & Temperature & \\
\hline A & Tubular & 0.923 & 0.8 & Blown $^{b}$ & $160^{\circ} \mathrm{C}$ & \\
\hline B & Tubular & 0.924 & 0.7 & Blown & $160^{\circ} \mathrm{C}$ & \\
\hline $\mathrm{C}$ & Tubular & 0.918 & 4.0 & $\mathrm{Cast}^{\mathrm{c}}$ & $260^{\circ} \mathrm{C}$ & \\
\hline $\mathrm{D}$ & Autoclave & 0.918 & 8.0 & Cast & $260^{\circ} \mathrm{C}$ & \\
\hline $\mathrm{E}$ & Autoclave & 0.924 & 4.0 & Cast & $260^{\circ} \mathrm{C}$ & \\
\hline F-1 & Autoclave & 0.923 & 3.7 & Cast & $260^{\circ} \mathrm{C}$ & \\
\hline$F-2$ & & & & & $300^{\circ} \mathrm{C}$ & \\
\hline F-3 & & & & & $260^{\circ} \mathrm{C}$ & BHT \\
\hline$F-4$ & & & & & $260^{\circ} \mathrm{C}$ & Oleylamide \\
\hline
\end{tabular}

a Melt index is defined as the amount of resin that will flow through a given orifice dimension in ten minutes under a given pressure at a specified temperature.

ㅇ Blown film is produced by extruding through a circular orifice, inflating the tube with air to a desired diameter, and pulling it away with a pair of nip rolls.

c Cast film is produced by extruding through a slot die onto a polished chill roll and cooling rapidly.

shows the method for polymerization of ethylene, properties of the resin such as density and melt index, process and temperature for film-formation, and additives for each film. In addition to these, six varieties of film formed at temperatures of 240,270 , and $300^{\circ} \mathrm{C}$, using the resins of films $\mathrm{C}$ and $\mathrm{E}$ were also prepared only as unirradiated samples.

2. Irradiation with electron beams. Two grams of polyethylene film was cut into small pieces and placed in a $100 \mathrm{ml}$ tightly closed flask. The film was irradiated with a surface dose of about $20 \mathrm{kGy}$ in air at room temperature using a Van de Graaff electron accelerator. Acceleration voltage and beam current were $2.5 \mathrm{MV}$ and $250 \mu \mathrm{A}$, respectively, at a conveyor speed of $2 \mathrm{~m} / \mathrm{min}$. Dosimetry was performed using CTA film (Fuji Photo Film Co.).

3. Determination of conditions for trapping volatiles from irradiated film. The volatiles from irradiated film F-1, which gave the strongest off-odor, were concentrated using a trapping apparatus (Gasukuro Kogyo Co.) shown in Fig. 1. Column A was packed with $140 \mathrm{mg}$ of Tenax GC of $60 / 80$ mesh and held at room temperature. Nitrogen gas at a flow rate of $20 \mathrm{ml} / \mathrm{min}$ was passed through the flask which was incubated at temperatures from 25 to $98^{\circ} \mathrm{C}$. The trapped volatiles were desorbed at $200^{\circ} \mathrm{C}$ and swept by nitrogen gas at a flow rate of $50 \mathrm{ml} / \mathrm{min}$ into a gas chromatograph (Shimadzu GC7AG). The conditions for gas chromatography are shown in Table II.

4. Measurement of the gross amounts of carboxylic acids produced by irradiation. The procedure of trapping and gas

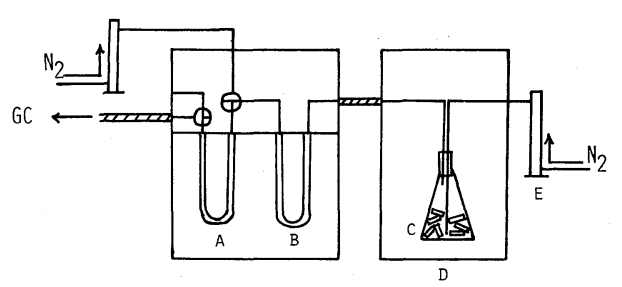

FIG. 1. Trapping Apparatus for Volatile Compounds. A, column packed with Tenax GC; B, water trap; C, sample; D, incubator; E, flow meter.

TABle II. Conditions for Gas Chromatography

\begin{tabular}{ll}
\hline Packing: & Ucon oil $\mathrm{HB} 2000, \mathrm{LB} 550 \mathrm{X}$ \\
Column size: & $80 \mathrm{~m} \times 0.23 \mathrm{~mm} \phi$ \\
Column temperature: & $60^{\circ} \mathrm{C}(16 \mathrm{~min}) \rightarrow 140^{\circ} \mathrm{C} 4^{\circ} \mathrm{C} / \mathrm{min}$ \\
Carrier gas: & $\mathrm{N}_{2} 0.43 \mathrm{ml} / \mathrm{min}$ \\
Detector: & FID \\
\hline
\end{tabular}

chromatography of the volatiles from irradiated film F-1 was repeated several times until almost no carboxylic acids were detected. The amounts of carboxylic acids were calculated as the total quantities of those trapped.

5. Analysis of the volatiles from unirradiated film. Since the amounts of the volatiles from unirradiated film were much smaller than those of irradiated film, sixty grams of unirradiated film were used for concentration of the volatiles. The volatiles were trapped on Tenax GC by passing three liters of nitrogen gas through the trapping apparatus; they were analyzed by gas chromatography under the conditions shown in Table II. 


\section{RESULTS AND DISCUSSION}

\section{Concentration and determination method of carboxylic acids}

a) Temperature of sample incubation. The relationship between the temperature of sample incubation and the quantities of carboxylic acids from irradiated polyethylene is shown in Fig. 2. The quantities of all four carboxylic acids increased with an increase in temperature up to $80^{\circ} \mathrm{C}$, and remained at almost the same level except $n$-valeric acid at higher temperatures up to $98^{\circ} \mathrm{C}$. This result indicates that the optimum incubating temperature is $80^{\circ} \mathrm{C}$.

b) Volume of nitrogen gas passed for trapping of volatiles. The relationship between the volume of nitrogen gas passed for trapping of volatiles and the quantities of carboxylic acids is shown in Fig. 3. Carboxylic acids increased with an increase in the volume of nitrogen gas until it reached 0.9 liter and then decreased. The extent of the decrease was related to the volatility of carboxylic acids. Porous polymer beads, such as Tenax GC, usually have limited capacities for trapping organic compounds, and the capacity of Tenax GC has been evaluated with the breakthrough volumes of ninety kinds of organic compounds by Kawata et al. ${ }^{7)}$ The breakthrough volume increased exponentially with an increase in the boiling point or molecular weight of organic compound. In measuring the amounts of each compound in a mixture as in our study, the volume of nitrogen gas should be lower than the level which saturates the quantity of each compound absorbed to Tenax GC. The results in Fig. 3 show that a volume of nitrogen gas of 0.6 liter is suitable to reserve an ample capacity for adsorption. When 0.6 liter of nitrogen gas was passed through a flask containing propionic acid and acetone at $80^{\circ} \mathrm{C}, 97 \%$ of the head space gas was replaced.

c) Reproducibility. The quantities of trapped carboxylic acids were measured using the sample irradiated with electron beams under the same conditions for irradiation in order to confirm reproducibility. The averages of peak

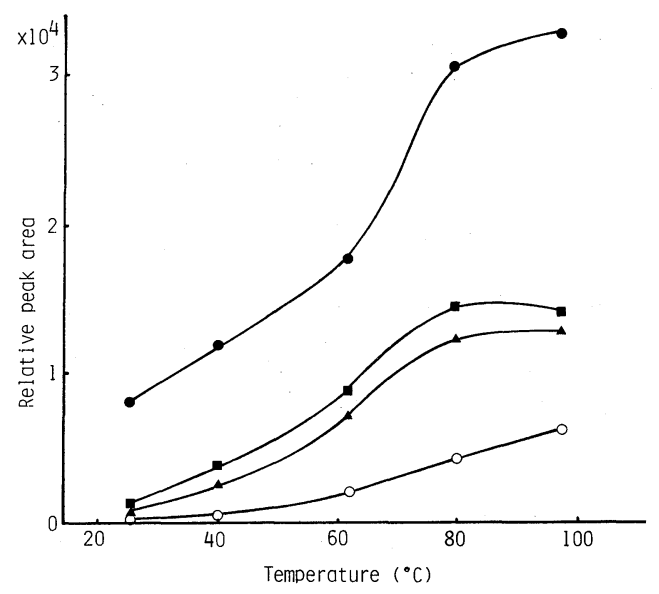

FIG. 2. Relationship between the Temperature of Sample Incubation and Quantities of Carboxylic Acids from Irradiated Polyethylene.

The volatiles from film incubated at various temperatures were trapped by passing nitrogen gas at a flow rate of $20 \mathrm{ml} / \mathrm{min}$ for $30 \mathrm{~min}$ and the quantities of carboxylic acids were determinend by gas chromatography. $\mathbf{0}$, acetic acid; $\mathbf{Q}$, propionic acid; $\boldsymbol{\Delta}, n$-butyric acid; $\bigcirc, n$-valeric acid.

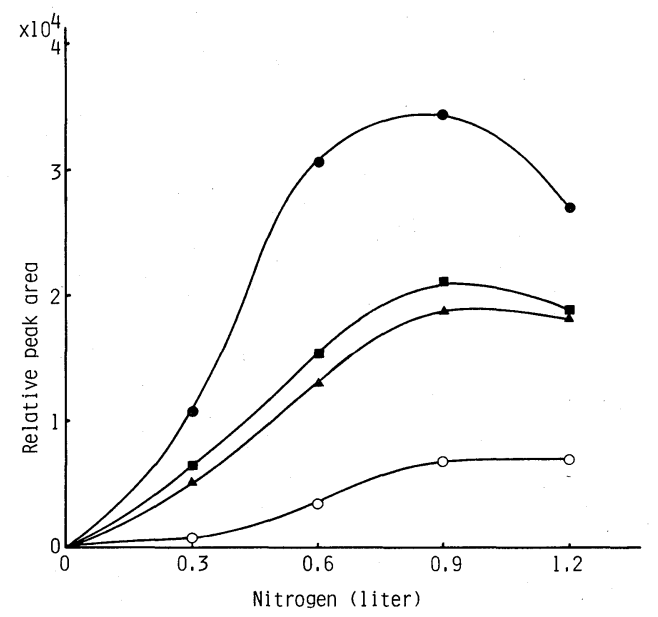

FIG. 3. Relationship between the Volume of Nitrogen Gas Passed for Trapping and the Quantities of Carboxylic Acids from Irradiated Polyethylene.

The volatiles from film incubated at $80^{\circ} \mathrm{C}$ were trapped by passing different volume of nitrogen gas at a flow rate of $20 \mathrm{ml} / \mathrm{min}$ and the quantities of carboxylic acids were determined by gas chromatography. $\mathbf{O}$, acetic acid; $\mathbf{D}$, propionic acid; $\boldsymbol{\Delta}, n$-butyric acid; $\bigcirc, n$-valeric acid.

areas, standard deviations, and variation coefficients in four measurements are shown in Table III. The variation coefficient of pro- 
Table III. ReProducibility of the Quantities of Trapped Carboxylic Acids

\begin{tabular}{|c|c|c|c|c|}
\hline \multirow{2}{*}{ Measurement } & \multicolumn{4}{|c|}{ Peak area } \\
\hline & Acetic acid & Propionic acid & $\dot{n}$-Butyric acid & $n$-Valeric acid \\
\hline 1 & 30799 & 14495 & 12377 & 3461 \\
\hline 2 & 31029 & 12307 & 11783 & 3204 \\
\hline 3 & 32341 & 14800 & 13433 & 3237 \\
\hline 4 & 32513 & 15396 & 13349 & 3502 \\
\hline Average & 31671 & 14250 & 12736 & 3351 \\
\hline Standard deviation & 763 & 1167 & 689 & 132 \\
\hline Variation coefficient ${ }^{a}(\%)$ & 2.4 & 8.2 & 5.4 & 3.9 \\
\hline
\end{tabular}

a $\quad$ Variation coefficient $=($ standard deviation/average $) \times 100$.

pionic acid was relatively high, but all were smaller than $10 \%$. Considering that the variation of observed values would be caused by the difference in the amounts of carboxylic acids produced and the experimental error, the reproducibility is quite good.

d) Gross amounts of carboxylic acids produced by irradiation. When the procedure of trapping for 30 minutes at $80^{\circ} \mathrm{C}$ and gas chromatography of carboxylic acids released from irradiated film F-1 was repeated, the quantities of trapped acids decreased as shown in Fig. 4. Acetic acid, which is the most volatile, could almost not be detected in the fifth trapping, while the others were absent in the sixth trapping. The quantities of acetic acid, propionic acid, $n$-butyric acid, and $n$ valeric acid collected in the first trapping occupied $81,72,65$, and $56 \%$ of their total amounts, respectively, which decreased with a decrease in volatility.

The amounts of carboxylic acids produced per gram of irradiated film F-1 were about $9.9 \mu \mathrm{g}$ for acetic acid, $8.5 \mu \mathrm{g}$ for propionic acid, $1.7 \mu \mathrm{g}$ for $n$-butyric acid, and $0.9 \mu \mathrm{g}$ for $n$-valeric acid.

\section{The amounts of carboxylic acids from va-} rious kinds of unirradiated films

Each of the unirradiated films showed a different pattern of gas chromatogram and the amounts of carboxylic acids were insignificant. The effect of the temperature of film-formation on the amounts of carboxylic acids was in-
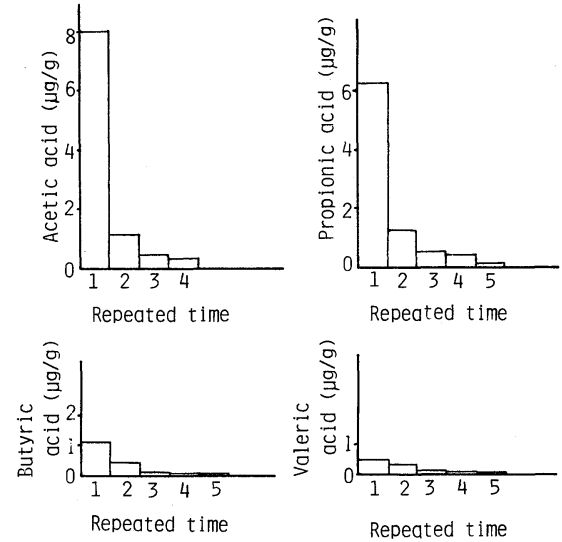

FIG. 4. Amounts of Carboxylic Acids Produced in Irradiated Polyethylene Film F.

The volatiles from irradiated film were trapped 5 to 6 times until carboxylic acids were almost not detected and the gross amounts of carboxylic acids were determined.

vestigated using the films formed at different temperatures between 240 and $300^{\circ} \mathrm{C}$. The amounts of carboxylic acids increased with an increase in temperature of film formation. Particularly, the film formation at $300^{\circ} \mathrm{C}$ increased the total amount of acids to more than ten times that of the film formed at $270^{\circ} \mathrm{C}$. Film formation at a lower temperature would be desirable for the preparation of film having a low level of odor. Addition of $0.25 \%$ butylated hydroxytoluene (BHT) as an antioxidant in the film formation at $300^{\circ} \mathrm{C}$ was effective to reduce the formation of carboxylic acids; acetic acid and propionic acid were reduced to 34 and $18 \%$, respectively, and $n$-valeric acid was 
Table IV. Comparison of the Amounts of Carboxylic Acids Produced in Low Density Polyethylene Film

\begin{tabular}{|c|c|c|c|c|c|c|c|c|c|}
\hline \multirow{3}{*}{ Film } & \multicolumn{9}{|c|}{ Carboxylic acids } \\
\hline & \multicolumn{2}{|c|}{ Acetic } & \multicolumn{2}{|c|}{ Propionic } & \multicolumn{2}{|c|}{$n$-Butyric } & \multicolumn{2}{|c|}{$n$-Valeric } & \multirow{2}{*}{$\begin{array}{l}\text { Total } \\
(\mu \mathrm{g} / \mathrm{g})\end{array}$} \\
\hline & $(\mu \mathrm{g} / \mathrm{g})$ & $(\%)$ & $(\mu \mathrm{g} / \mathrm{g})$ & $(\%)$ & $(\mu \mathrm{g} / \mathrm{g})$ & $(\%)$ & $(\mu \mathrm{g} / \mathrm{g})$ & $(\%)$ & \\
\hline A & 7.26 & 58.5 & 4.10 & 33.0 & 0.73 & 5.9 & 0.33 & 2.7 & 12.42 \\
\hline B & 6.80 & 57.5 & 4.12 & 34.9 & 0.61 & 5.2 & 0.29 & 2.5 & 11.82 \\
\hline $\mathrm{C}$ & 4.65 & 61.3 & 2.37 & 31.3 & 0.37 & 4.9 & 0.19 & 2.5 & 7.58 \\
\hline $\mathrm{D}$ & 3.10 & 59.7 & 1.64 & 31.6 & 0.29 & 5.6 & 0.16 & 3.1 & 5.19 \\
\hline E & 6.23 & 42.5 & 6.69 & 45.7 & 1.26 & 8.6 & 0.47 & 3.2 & 14.65 \\
\hline F-1 & 7.95 & 50.8 & 6.15 & 39.3 & 1.11 & 7.1 & 0.45 & 2.9 & 15.66 \\
\hline $\mathrm{F}-2$ & 7.21 & 62.5 & 3.34 & 29.0 & 0.69 & 6.0 & 0.29 & 2.5 & 11.53 \\
\hline F-3 & 1.37 & 74.9 & 0.19 & 10.4 & 0.23 & 12.6 & 0.04 & 2.2 & 1.83 \\
\hline F-4 & 6.27 & 68.1 & 2.37 & 25.7 & 0.44 & 4.8 & 0.13 & 1.4 & 9.21 \\
\hline
\end{tabular}

not detected.

\section{The amounts of carboxylic acids from sev-} eral varieties of irradiated polyethylene film The quantities of carboxylic acids obtained in the first trapping from nine varieties of irradiated film are shown in Table IV. It became evident that the amounts of carboxylic acids produced by electron beam irradiation varied considerably depending upon the properties of resin, temperature of film-formation, or the presence of additives and that the effect of the addition of an antioxidant on the formation of carboxylic acids was greater than those of the properties of resin or temperature of film-formation.

Film F-1 produced the largest amounts of carboxylic acids of the six varieties of irradiated film without additives (A to $\mathrm{F}-1$ ) and the total amount was about three times that of film $\mathrm{D}$ which gave the smallest amounts. The amounts of carboxylic acids of unirradiated film had little correlation with the amounts of acids from irradiated film. Density of resin showed a relatively high correlation to the amounts of carboxylic acids formed by irradiation and the coefficient of correlation was 0.898 . Films $\mathrm{E}$ and F-1 were different from the others in the ratios of the amounts of three carboxylic acids; the ratios of propionic acid and $n$-butyric acid were higher and the ratio of acetic acid was lower.
Film F-2, which was formed at a higher temperature of $300^{\circ} \mathrm{C}$, produced slightly less carboxylic acids than film F-1 and the effect of temperature of film-formation on the offodor from irradiated film was not important. Addition of $0.2 \%$ of oleylamide for slipping in film F-4 reduced the formation of carboxylic acids to less than $60 \%$ compared with film F-1. In film F-3, to which BHT was added, very small amounts of carboxylic acids were produced when it was irradiated with electron beams; they were only about $12 \%$ compared with film F-1. According to the report by Skiens, ${ }^{3)}$ the materials containing aromatic compounds show good resistance to radiation. It is estimated that the oxidation of polyethylene induced by irradiation is based on the general scheme of autoxidation reactions established for smaller molecules ${ }^{8 \sim 11}$; oxygen reacts with a polyethylene radical and the resulting peroxy radical is subsequently decomposed. The action of antioxidants might be to combine rapidly with radiation-generated free radicals in the polymer or to transform peroxy radicals into inactive species. It is suggested that radiation under atmospheres not containing oxygen is effective to restrain the formation of carboxylic acids.

\section{REFERENCES}

1) F. J. Ley, J. Soc. Cosmet. Chem., 27, 483 (1976). 
2) H. Landfield, Radiat. Phys. Chem., 15, 39 (1980).

3) W. E. Skiens, Radiat. Phys. Chem., 15, 47 (1980).

4) V. R. Carlson, Package Engineering Including Modern Packaging, The Packaging Encyclopedia, 1983, p. 127.

5) K. Azuma, T. Hirata, H. Tsunoda, T. Ishitani and Y. Tanaka, Agric. Biol. Chem., 47, 855 (1983).

6) P. E. Jacobs, Package Engineering including Modern
Packaging, The Packaging Encyclopedia, 1983, p. 74.

7) K. Kawata, T. Uemura, I. Kifune, Y. Tominaga and K. Oikawa, Bunseki Kagaku, 31, 453 (1982).

8) N. Grassic, "Chemistry of High Polymer Degradation Processes,” Interscience, 1956, p. 160.

9) M. Magat, Radiation Res. Suppl., 1, 204 (1959).

10) C. Walling, Radiation Res. Suppl., 3, 3 (1963).

11) A. Chapiro, Radiation Res. Suppl., 4, 179 (1964). 